\title{
Aporte sedimentar em suspensão na bacia do rio Machado, sul de Minas Gerais
}

\author{
Suspended sediment yield in the Machado river basin, Southern of Minas Gerais
}

\author{
Marcelo de Oliveira Latuf \\ Professor do Programa de Pós-graduação em Geografia da \\ Universidade Federal de Alfenas, MG, Brasil \\ marcelo.latuf@unifal-mg.edu.br \\ Denis Giovanni Musselli \\ Discente do curso de Geografia da \\ Universidade Federal de Alfenas, MG, Brasil \\ denismusselli@terra.com.br \\ Hanna Sayuri de Souza Chinen \\ Discente do curso de Geografia da \\ Universidade Federal de Alfenas, MG, Brasil \\ hanna.sayuri@yahoo.com \\ Pedro Henrique Silva Carvalho \\ Discente do curso de Geografia da \\ Universidade Federal de Alfenas, MG, Brasil \\ pedrocarvalhogeo@gmail.com
}

\section{Resumo}

O processo de erosão hídrica é uma ação natural que ocorre ao longo do tempo geológico e geomorfológico e que pode ser impulsionado pela ação antrópica, quando da modificação do uso e cobertura da terra. Para além dos impactos do processo erosivo quanto à perda de fertilidade dos solos, a erosão hídrica causa nos sistemas fluviais um aporte de partículas de variadas granulometrias, que são postas em transporte, em função de características do escoamento em vertentes e canais. Com a chegada das partículas desprendidas das vertentes, alterações no padrão da turbidez são notadas, impactando a qualidade da água para fins de abastecimento humano, contribuindo para o assoreamento de canais e represas, pelo decaimento de taxa fotossintética e transporte de agroquímicos adsorvidos. Nesse contexto, enquadra-se a bacia hidrográfica do rio Machado, localizada no sul de Minas Gerais, que integra a Área de Proteção Ambiental do rio Machado. O presente artigo possui como objetivo avaliar o aporte de sedimentos em suspensão no rio Machado, próximo à cidade de Machado/MG, auxiliando o conhecimento do regime sedimentar na bacia, além de contribuir com ações voltadas à conservação do solo e água e minimização de processos erosivos. Foram utilizados dados coletados pelo IGAM entre 2007 e 2017, com relação à concentração de sedimentos em suspensão $\left(\mathrm{mg} . \mathrm{L}^{-1}\right)$, turbidez (UNT) e vazão $\left(\mathrm{m}^{3} \cdot \mathrm{s}^{-1}\right)$, bem como dados pluviométricos $(\mathrm{mm})$ da ANA. Foram realizadas análises baseadas em estatística descritiva, análise de correlações e de estacionariedade. Resultados indicam que - em média - no período-base utilizado o aporte sedimentar do rio Machado situa-se em 49,9 t.dia ${ }^{-1}$, não havendo mudança significativa no comportamento do aporte sedimentar e que há correlação de 0,94 entre turbidez e concentração de sólidos em suspensão.

Palavras-chave: Hidrossedimentologia, Unidade de conservação, Carga sedimentar, Assoreamento. 


\begin{abstract}
The water erosion process is a natural action that occurs along geological and geomorphological time and can be performed by anthropic action when there is land use change. In addition to the impacts of the erosive process on the loss of soil fertility, water erosion causes in fluvial systems a contribution of particles of various granulometries that are put in transport, due to the characteristics of the flow in slopes and channels. With the arrival of particles detached from the slopes, changes in the turbidity pattern are noticed, impacting the quality of water for human supply, contributing to the channels and dams aggradation, the decay of photosynthetic rate and transport of adsorbed agrochemicals. In this context, the Machado river basin located in the South of Minas Gerais, integrates the Environmental Protection Area of the Machado river. The aim of this article is to evaluate the contribution of suspended sediment yield at Machado river, near the city of Machado, Minas Gerais State, Brazil, therefore assisting the knowledge of the sedimentary regime in the basin, as well as contribute with actions aimed at soil and water conservation and minimization of the erosive process. Data were collected to the Minas Gerais Water Management Institute between 2007 and 2017 that were used for the suspended solid concentration $\left(\mathrm{mg} \cdot \mathrm{L}^{-1}\right)$, turbidity (NTU) and streamflow $\left(\mathrm{m}^{3} \cdot \mathrm{s}^{-1}\right)$, as well as rainfall data $(\mathrm{mm})$ of the Brazilian National Water Agency. Descriptive statistics and stationarity analyzes were performed to detect changes in the sedimentary regime. The results indicate that, on average, in the period researched the sediment yield of the Machado river was 49.9 t.day $^{-1}$, as well as there was no significant change in sediment contribution behaviour and there is a correlation of 0.94 between turbidity and suspended solid concentration.
\end{abstract}

Keywords: Hydrossedimentology, Conservation unit, Sediment load, Aggradation.

\title{
1. INTRODUÇÃO
}

A Hidrologia caracteriza-se por ser a ciência que se debruça no estudo da variabilidade espacial e temporal dos componentes do ciclo hidrológico. Um destes componentes, o atmosférico, é responsável pela entrada de matéria e energia no sistema bacia hidrográfica, por meio da precipitação, que em regiões intertropicais possui a característica marcante por ser majoritariamente na forma líquida.

Porém, cabe ressaltar que há um desbalanceamento na distribuição de matéria e energia no momento da transição entre os componentes atmosférico e terrestre, pois a intensidade pluviométrica $\left(\mathrm{mm} \cdot \mathrm{h}^{-1}\right)$, bem como a lâmina precipitada $(\mathrm{mm})$, variam espaço-temporalmente sobre a paisagem.

A chegada das gotas de chuva sobre a superfície terrestre pode direcionar-se a amplos espectros de destinações. Ao precipitar-se (1) a gota de chuva pode ser interceptada pelo dossel da vegetação, ficar retida no mesmo e regressar ao estado gasoso; (2) escorrer por troncos e galhos até chegar ao solo; (3) ser interceptada pelo dossel e sub-bosque e, finalmente, alcançar a superfície do solo; (4) precipitar-se novamente do dossel diretamente sobre o solo; (5) ou ainda, precipitar-se diretamente sobre o solo sem que haja a ação de uma cobertura vegetal.

As destinações supramencionadas ainda podem ocorrer de forma simultânea, a depender das fitofisionomias vegetacionais, bem como da sazonalidade de produção foliar das espécies e das características da precipitação. Uma vez chegada à superfície do solo, a água poderá ficar retida em inexpressivos volumes sobre a vegetação rasteira (serapilheira), infiltrar-se ou dar início ao 
escoamento superficial, a depender das características de umidade antecedente e da intensidade e lâmina pluviométrica.

Autores como Bertoni e Lombardi Neto (1990), Guerra (1999) e Pruski (2009) colaboraram expressivamente com a definição e caracterização do processo erosivo, em função de variáveis supracitadas.

Baseando-se em um pensamento sistêmico, encadeado por meio de complexas relações de interações no fluxo de matéria e energia entre os componentes do ciclo hidrológico (CHRISTOFOLETTI, 1981), o escoamento superficial inicia-se quando o volume precipitado supera a capacidade de infiltração de água na superfície do solo (PRUSKI, 2009) ou quando a microtopografia da superfície do solo não consegue manter retidos os volumes micro-armazenados (GUERRA, 1999).

Do início da precipitação (tempo igual a zero: $\mathrm{T}_{0}$ ) até o início do escoamento superficial (tempo igual a um: $\mathrm{T}_{1}$ ), é definido como abstrações iniciais, ou seja, um determinado período de tempo em que a vegetação e a microtopografia dos solos conseguem agir de forma eficiente no retardo do processo de escoamento (SHEEDER, 2002).

Tucci (2009) caracteriza a parcela da precipitação que origina o escoamento como precipitação efetiva, ou seja, a lâmina resultante da subtração entre as lâminas total precipitada e do período de abstração inicial. Entretanto, torna-se um desafio a caracterização deste intervalo de tempo em virtude das variações espaço-temporais dos tipos vegetacionais e seus respectivos estados vegetativos, bem como das características pedo-geomorfológicas da paisagem, de umidade antecedente dos solos e do uso e cobertura da terra.

Tendo o escoamento superficial se iniciado, a junção de pequenos veios de escoamento até a formação de enxurradas deve ser alvo de diagnóstico em virtude da necessidade de minimização de processos erosivos em bacias hidrográficas, tendo como foco o manejo e conservação da água e solo nesse sistema (BERTONI; LOMBARDI NETO, 1990). Algumas variáveis podem ser utilizadas na caracterização do escoamento superficial, dentre elas seu volume, velocidade e vazão, bem como aspectos da rugosidade e declividade dos canais e vertentes (OLIVEIRA, 2009).

O desprendimento das partículas de solo realizado pela tensão crítica de cisalhamento e seu transporte é feito pelo escoamento superficial acumulado e/ou difuso (GUERRA, 1999) e, quando o mesmo se conecta às redes de drenagens, há um aumento expressivo e abrupto na carga sedimentar transportada pelo sistema fluvial. O diagnóstico, monitoramento e modelagem do processo sedimentar realizado pelos sistemas fluviais é foco de estudo da geomorfologia fluvial ou da hidrossedimentologia. No que tange à geomorfologia fluvial, a escola anglo-saxônica, teve papel importante em sua estruturação ao longo do século XX, com trabalhos de Horton, Strahler, Chorley, Leopold, Schumm, Huggett dentre outros. No Brasil, pesquisadores como Antônio Christofoletti e 
Newton de Oliveira Carvalho destacam-se entre os percursores nos estudos hidrossedimentológicos, por meio das obras Geomorfologia Fluvial (CHRISTOFOLETTI, 1981) e Hidrossedimentologia Prática (CARVALHO, 1994), respectivamente.

O transporte de sedimentos nos sistemas fluviais é controlado por características do escoamento (volume, velocidade e vazão), bem como por seu regime (turbulento ou laminar) e pela rugosidade e gradiente dos canais. Dos materiais transportados encontram-se elementos inorgânicos e orgânicos, porém para o viés deste estudo permaneceremos focados no transporte de partículas de solo. O transporte de sedimentos já nas calhas de drenagens se dá por quatro formas preferenciais: arrasto, saltação, suspensão e dissolução (CUNHA, 2001), tendo destaque para a forma em suspensão que se coloca como a de maior expressividade.

Cada sistema fluvial, ao longo de seu perfil longitudinal, possui características variantes no tipo de transporte sedimentar, sendo necessária a caracterização não só dos processos e dos tipos de transportes, mas também nos padrões dos canais associados.

O sedimento quando inserido no sistema fluvial altera alguns parâmetros de qualidade de águas, como a transparência e a turbidez, alterando consequentemente a produção de oxigênio dissolvido na água (TUNDISI; TUNDISI, 2008), pois, a depender das concentrações de sedimento em suspensão no corpo hídrico, dificulta-se e/ou impede-se a penetração da luz solar, que é o propulsor de reações fotossintéticas.

Por outro lado, as alterações na concentração de sedimento em suspensão influenciam na reprodução de certas espécies da ictiofauna, como a do surubim na bacia do rio São Francisco. Só quando a água torna-se turva, devido à chegada do período das chuvas, que esta espécie inicia a piracema. Entretanto, obras hidráulicas como barragens atenuam o efeito de transporte de sedimento a jusante das mesmas, ocasionando um desequilíbrio no ecossistema reprodutivo em questão (PESCADOR, 2011).

O quadro supramencionado contribui para o processo de assoreamento de barragens, reduzindo o volume armazenado, bem como a vida útil destes reservatórios. Em virtude das alterações antrópicas no uso e cobertura da terra, acentuam-se as cargas de sedimentos transportados pelos sistemas fluviais, refletindo no aumento de taxas de sedimentação em sistemas lênticos de barramentos (CARVALHO, 2000).

Desta forma, o monitoramento das concentrações de sedimentos em suspensão deve ser realizado de forma extensiva ao longo dos cursos d'água nas bacias de drenagem, bem como em intervalos de tempo suficientemente capazes de diagnosticar as características deste fenômeno. Podese citar o amplo programa realizado pela Itaipu Binacional no monitoramento das cargas sedimentares nas principais bacias de contribuição que afluem ao lago da maior usina hidrelétrica brasileira. 
Um dos parâmetros utilizados no monitoramento das concentrações de sedimentos em suspensão é a turbidez, que representa a passagem de luz em um meio aquoso (VON SPERLING, 2005). A turbidez é um parâmetro de qualidade de água de fácil e rápida obtenção em campo ou em laboratório, a partir do uso de sondas ou leitores de bancada, respectivamente, e possui em geral boa correlação estatística, o que auxilia na relação custo-benefício em programas de monitoramento.

Diversos autores como Walling (1977), Horowitz (2003), Latuf e Amaral (2016), dentre outros, ajustaram estatisticamente parâmetros de concentração de sedimento em suspensão e vazão de diversos sistemas fluviais, procedimento conhecido como curva-chave de descarga sólida, para a estimativa da descarga sólida em suspensão, expressa em toneladas por dia (t.dia ${ }^{-1}$ ), auxiliando na quantificação do aporte sedimentar de bacias hidrográficas.

Neste contexto, enquadra-se o lago da Usina Hidrelétrica de Furnas (UHE Furnas), localizada no sul do Estado de Minas Gerais, tendo sua construção da barragem iniciada em julho de 1958 e a formação do lago para geração de energia em setembro de 1963 (FURNAS, 2019).

Operada por Furnas Centrais Elétrica S.A. a UHE Furnas possui a capacidade de geração de 1.216 MW, com volume total de 22,95 hm³ e volume útil de 17,21 hm³ (FURNAS, 2019), o lago possui uma expressiva área de inundação, correspondente a aproximadamente $1.340 \mathrm{~km}^{2}$ quando atingido seu volume útil de 100\% (ANA, 2019).

A área de drenagem da UHE Furnas possui aproximadamente $51.950,1 \mathrm{~km}^{2}$, tendo como principais afluentes os rios Grande, Sapucaí, Verde, Mortes, Jacaré e Machado. A preocupação centraliza-se no aporte sedimentar afluente ao lago da represa de Furnas, podendo causar o assoreamento e redução da capacidade de armazenamento de água para geração de energia, abastecimento humano, dessedentação de animais, piscicultura dentre outros múltiplos usos.

No estado de Minas Gerais, o Instituto Mineiro de Gestão de Águas (IGAM) caracteriza-se por ser o órgão responsável pelo planejamento e gestão dos recursos hídricos. Em suas diversas linhas de ação, o IGAM estabeleceu uma política de monitoramento de águas superficiais de forma sistemática desde 1997, tendo o adensamento da rede sido gradativamente incrementado. Os dados das amostras de água no âmbito do estado de Minas Gerais ficam disponíveis ao público pelo website do Portal InfoHidro (IGAM, 2019).

Tendo em vista as complexas transformações na paisagem da bacia hidrográfica da UHE Furnas e a necessidade de diagnóstico da dinâmica sedimentar afluente, este estudo objetiva a avaliação da carga sedimentar em suspensão do rio Machado, focando na obtenção de ajustamentos estatísticos entre os parâmetros de qualidade de água, bem como da precipitação acumulada, fomentando dados e informações ao Comitê da Bacia Hidrográfica do Entorno do Reservatório de Furnas (Comitê GD3) em ações de planejamento e gestão dos recursos hídricos. 


\section{MATERIAIS E MÉTODOS}

\subsection{Localização e caracterização da bacia de estudo}

A bacia hidrográfica do rio Machado localiza-se no sul de Minas Gerais, tendo como principais afluentes os ribeirões Machadinho do Campo e Machadinho, ambos à margem direita, e o ribeirão Jacutinga à margem esquerda. O rio Machado possui um relevante gradiente altimétrico em seu trecho de alto-médio curso, onde foi instalada em 1945 a Pequena Central Hidrelétrica Poço Fundo (CEMIG, 2019).

O IGAM possui desde 2007 um ponto de monitoramento da qualidade de água superficial do rio Machado (Figura 1), a jusante da cidade de Machado/MG, localizado nas coordenadas $21,67^{\circ} \mathrm{S}$ e 45,89 ${ }^{\circ} \mathrm{W}$, nas proximidades da ponte sobre o rio Machado na MG-179 (Figura 2), a $3 \mathrm{~km}$ do trevo com a BR-267, que dá acesso à cidade de Machado/MG, tendo área de drenagem de 775 km² .

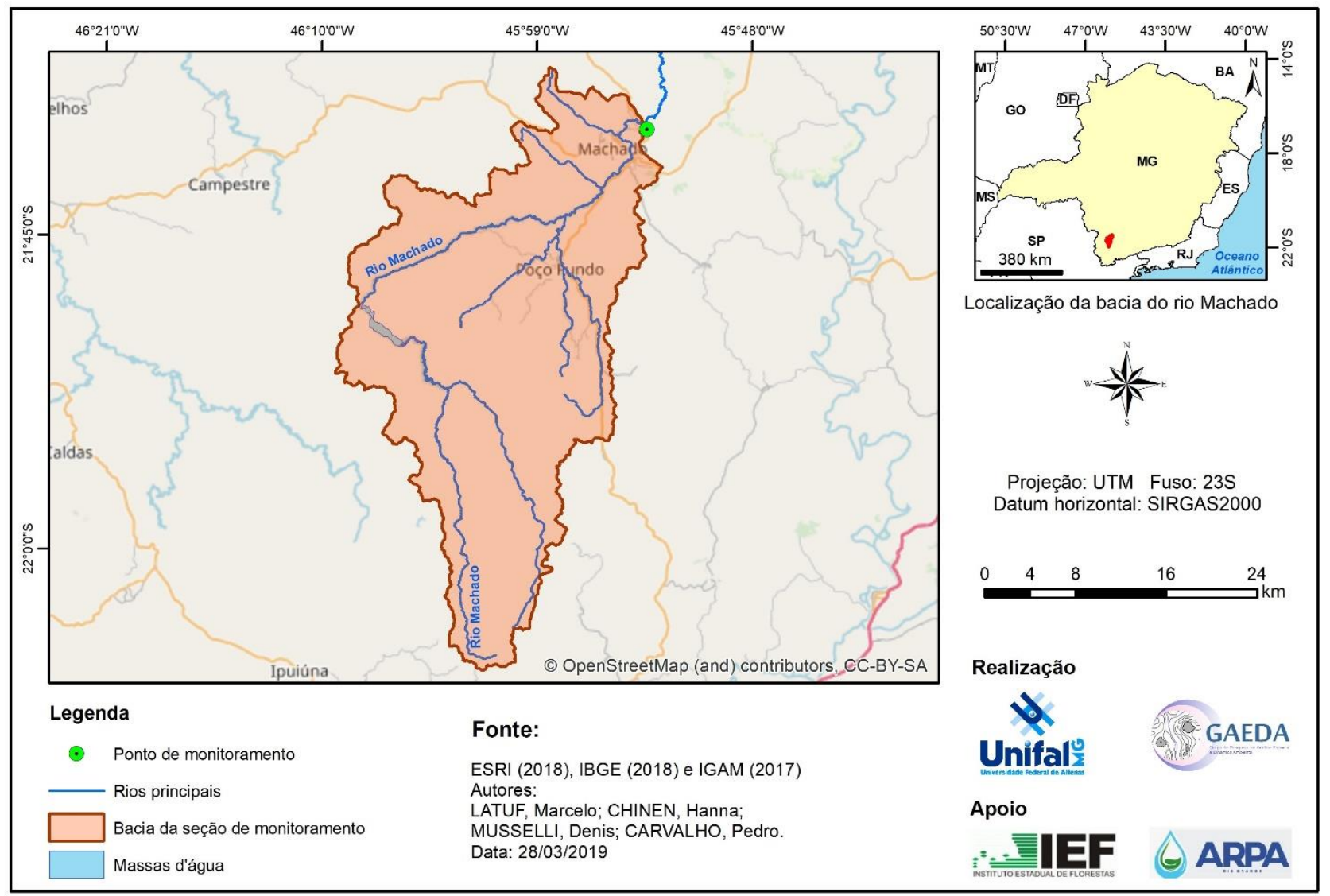

Figura 1 - Localização da seção de monitoramento de águas superficiais Fonte: Autores, 2019.

Em mapeamento elaborado pela Companhia de Desenvolvimento Econômico de Minas Gerais (CODEMIG), em conjunto com a Companhia de Pesquisa e Recursos Minerais (CPRM), identificaram-se formações litológicas do tipo granito-gnaisses com litotipos paragnaisse, ortognaisse, quartizito, migmatito, biotita xisto e granitoides associados (CPRM, 2014). 

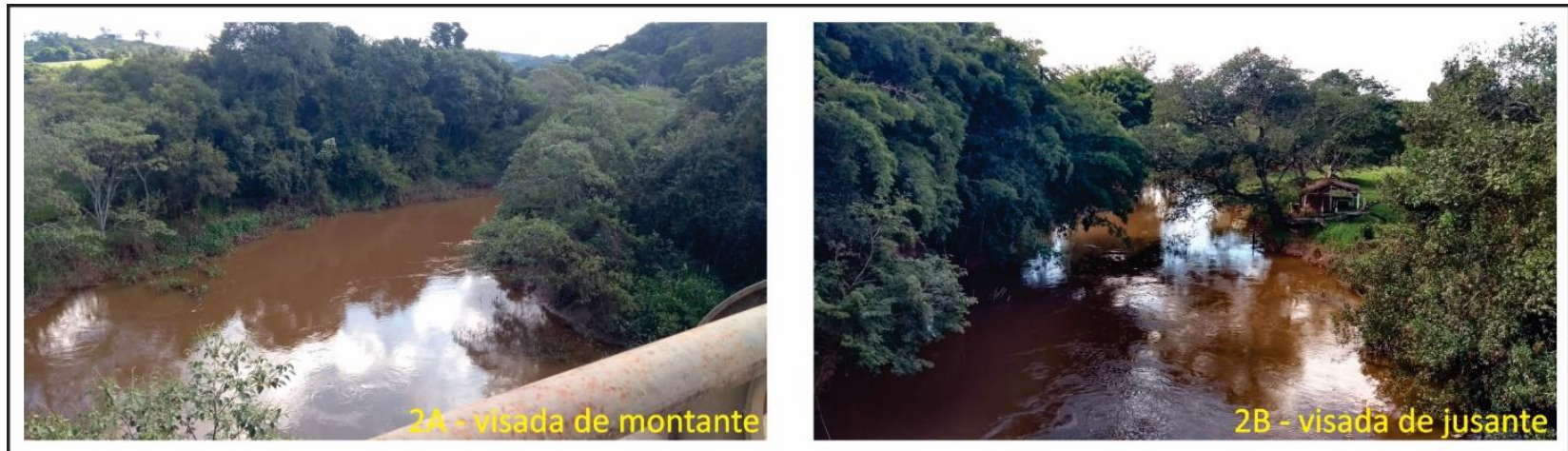

Figura 2 - Visualização da seção de monitoramento de águas no rio Machado Fonte: Autores, 2019.

Gregório e Ferreira (2018) elaboraram mapeamento de compartimentos morfológicos ao nível do $3^{\circ}$ táxon para a Área de Proteção Ambiental da Bacia Hidrográfica do rio Machado (APA rio Machado), baseando-se na metodologia de mapeamento geomorfológico proposta por Ross (1992), apontando a ocorrência de seis compartimentos geomorfológicos, divididos em formas de dissecação e agradação.

Quanto às unidades pedológicas na bacia de drenagem a montante da seção de monitoramento, predominam a ocorrência de Latossolos e Cambissolos, com 59,8\% e 33,7\%, respectivamente (UFV, 2010).

O tipo climático reinante na área de estudo é caracterizado pelo clima Tropical de Altitude (Cwa), com duas estações definidas, uma chuvosa de outubro até março e outra seca, de abril a setembro (ALVARES, 2013; REBOITA, 2015). De acordo com dados da estação climatológica Machado (código 83683), operada pelo Instituto Nacional de Meteorologia (INMET), no período de 1981 a 2010, a temperatura média anual compensada situa-se em $20,1^{\circ} \mathrm{C}$, sendo fevereiro o mês mais quente com média de $29,5^{\circ} \mathrm{C}$ e julho o mês mais frio, com média mínima mensal de $9,5^{\circ} \mathrm{C}$. Já a pluviosidade média anual fica em torno de $1.555,9 \mathrm{~mm}$, sendo janeiro o mês mais chuvoso com média de 309,1 mm (INMET, 2019).

O tipo vegetacional predominante é de Mata Atlântica, com faixas de transição para fitofisionomias de Cerrado nas regiões mais elevadas da bacia. Dados obtidos por Pisani (2018) destacam que $41,7 \%$ da cobertura vegetacional na bacia ainda permanecem originais, porém relata que diversos usos agrícolas converteram $350,4 \mathrm{~km}^{2}$ em áreas antropizadas.

No que tange às áreas antropizadas, a porção sul do estado de Minas Gerais baseia-se predominantemente no plantio e beneficiamento da cultura do café tipo arábica (Coffea arabica), produto este destinado ao atendimento do mercado nacional, mas principalmente ao mercado externo. De acordo com dados obtidos no Instituto Brasileiro de Geografia e Estatística (IBGE) a estimativa de produção de café alcança 28.282,2 toneladas/ano, apenas para o município de Machado/MG, caracterizando-se como o maior produtor regional (IBGE, 2017). 
Com relação ao contingente populacional destacam-se os municípios de Machado/MG e Poço Fundo/MG, onde se inserem seus respectivos sítios urbanos na bacia de estudo e possuem estimativa populacional de 41.844 habitantes e 16.734 habitantes, respectivamente (IBGE, 2019).

\subsection{Aquisição e tratamento de dados hidrológicos}

Os procedimentos metodológicos deste estudo foram pautados em duas etapas (Figura 3), sendo a primeira caracterizada pela aquisição e seleção de dados hidrológicos, já a segunda consistiu no tratamento e análise dos dados obtidos.

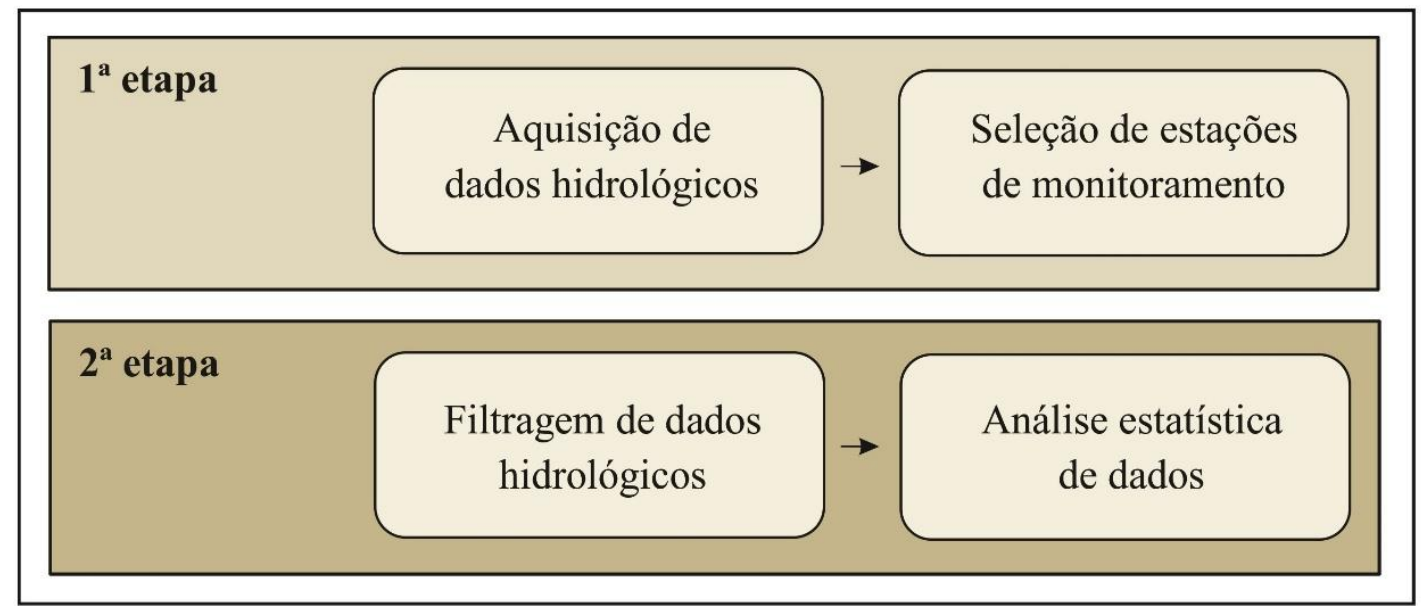

Figura 3 - Organograma metodológico da pesquisa Fonte: Autores, 2019.

O IGAM possui um programa de monitoramento de qualidade de águas superficiais no Estado de Minas Gerais de forma sistemática e por meio do acesso aos dados da série histórica de monitoramento, pelo website http://portalinfohidro.igam.mg.gov.br/, na sessão Monitoramento de Qualidade das Águas, realizou-se a aquisição das séries históricas de dados de 1997 a 2017, dos parâmetros de qualidade.

Ainda na fase de aquisição de dados utilizaram-se valores diários de precipitação ( $\mathrm{mm})$, com antecedência de três dias às amostragens dos parâmetros de qualidade de águas, de estações pluviométricas da Agência Nacional de Águas (ANA) pelo sistema Hidroweb (http://www.snirh.gov.br/hidroweb/publico/apresentacao.jsf) e do Instituto Nacional de Meteorologia (INMET), pelo sistema do Banco de Dados Meteorológicos para Ensino e Pesquisa (BDMEP) no endereço http://www.snirh.gov.br/hidroweb/publico/apresentacao.jsf, códigos 02146029 e 83683, respectivamente. A lâmina antecedente foi obtida pelo método de média aritmética dos postos supramencionados, devido à rarefeita rede hidrometeorológica presente na área de estudo (TUCCI, 2009). 
Os dados obtidos sobre qualidade de águas estão sistematizados em forma de planilhas eletrônicas para todas as Unidades de Planejamento e Gerenciamento de Recursos Hídricos do Estado de Minas Gerais (UPGRH), e desta forma fez-se necessária a seleção da planilha da bacia do rio Grande e, consequentemente, exclusão dos dados referentes às demais UPHRHs.

Concluída a fase de aquisição de dados, deu-se início à fase de seleção de estações de monitoramento, onde focou-se na seleção de amostras da estação Rio Machado (código BG069), localizada no rio Machado, a jusante da sede urbana de mesmo nome. Este procedimento foi realizado no período de 2007 a 2018, pois foi identificada a inexistência de amostras na UPGRH entorno do lago de Furnas em período anterior a 2007.

A segunda etapa teve como objetivos a filtragem dos dados dos parâmetros de qualidade de águas monitorados pelo IGAM referentes à dinâmica sedimentar em suspensão, bem como a análise estatística dos dados. A fase de filtragem de dados hidrológicos da estação BG069 consistiu na seleção de dados de vazão $\left(\mathrm{m}^{3} \cdot \mathrm{s}^{-1}\right)$, sólidos em suspensão totais $\left(\mathrm{mg} \cdot \mathrm{L}^{-1}\right)$ e turbidez (UNT), sendo os demais dados excluídos desta análise.

As análises estatísticas dos dados consistiram na obtenção da correlação Pearson (R) entre a variável precipitação antecedente de três dias $(\mathrm{mm})$ com os dados de sólidos em suspensão totais (SST), turbidez e descarga sólida em suspensão (t.dia $\left.{ }^{-1}\right)$, bem como entre as variáveis turbidez e sólidos em suspensão totais.

A obtenção da estimativa de descarga sólida em suspensão (Equação 1) foi sustentada pelo método proposto por Carvalho (2000),

$$
Q S S=(Q * S S T) * 0,0864
$$

onde,

QSS: descarga sólida em suspensão (t.dia $\left.{ }^{-1}\right)$

Q: vazão diária $\left(\mathrm{m}^{3} \cdot \mathrm{s}^{-1}\right)$

SST: sólidos em suspensão total (mg.L $\left.\mathrm{L}^{-1}\right)$

0,0864: fator de correção de unidades

Utilizou-se o coeficiente de determinação da regressão linear $\left(\mathrm{R}^{2}\right)$ para obtenção do ajuste entre os parâmetros de turbidez e sólidos em suspensão totais, precipitação antecedente de três dias e sólidos em suspensão totais e precipitação antecedente de três dias e descarga sólida em suspensão, todos com limiar de aceitação igual ou superior a 0,70 ao nível de 5\% de significância. 
A identificação de dados discrepantes seguiu a metodologia da Amplitude Interquartil (BERALDO; SALDANHA, 2016), obtida via processamento no software RStudio 1.0.153 (R CORE TEAM, 2018).

Para efeito de aferição ao cumprimento da Deliberação Normativa conjunta COPAM/CERH-MG no 01/2008 (MINAS GERAIS, 2008), referente aos limites máximos estabelecidos a parâmetros de qualidade de águas no Estado de Minas Gerais, analisaram-se as concentrações dos parâmetros turbidez e sólidos em suspensão totais ao longo da série histórica de dados.

\section{RESULTADOS E DISCUSSÃO}

Após sistematização dos dados obtidos pelo Portal InfoHidro do IGAM, constatou-se que na bacia hidrográfica do rio Machado, há apenas uma estação de monitoramento de qualidade de águas superficiais, com o período-base de dados entre 2007 e 2018. Porém, no momento de aquisição dos dados supramencionados, o ano de 2018 não havia sido completamente sistematizado pelo órgão gestor, o que levou a utilizarmos o período de 2007 a 2017, compreendendo 11 anos de observações com o total de 36 amostras $(n=36)$.

Identificou-se por meio das datas de coletas registradas que há uma periodização nas amostragens, destacando-se os meses de fevereiro, maio, agosto e novembro como sendo as maiores frequências de ocorrência, exceto para duas amostras coletadas no mês de outubro.

O Comitê GD3 ainda não possui o enquadramento dos corpos d'água segundo usos preponderantes e, desta forma, enquanto isto não ocorre, todos os cursos d'água são considerados como sistemas fluviais de Classe 2, de acordo com Artigo 42 da Resolução CONAMA 357/2005 (BRASIL, 2005). O Estado de Minas Gerais adota a Deliberação Normativa COPAM/CERH-MG $n^{\circ}$ 01/2008 (MINAS GERAIS, 2008), como referência aos limites máximos dos parâmetros turbidez e sólidos em suspensão totais para a Classe 2 (Tabela 1).

Tabela 1 - Limites máximos estabelecidos pela Deliberação Normativa COPAM/CERH-MG nº 01/2008

\begin{tabular}{c|c|c}
\hline $\begin{array}{c}\text { Parâmetro de qualidade de água } \\
\text { (Classe 2) }\end{array}$ & Unidade & Valor \\
\hline Turbidez & UNT & 100 \\
\hline Sólidos em Suspensão Totais & $\mathrm{mg} . \mathrm{L}^{-1}$ & 100 \\
\hline
\end{tabular}

Fonte: MINAS GERAIS, 2008.

Baseando-se nos critérios expostos na Tabela 1 foi elaborada a Figura 4, onde se evidenciam os comportamentos dos parâmetros turbidez (Figura 4A) e sólidos em suspensão totais (Figura 4B). 


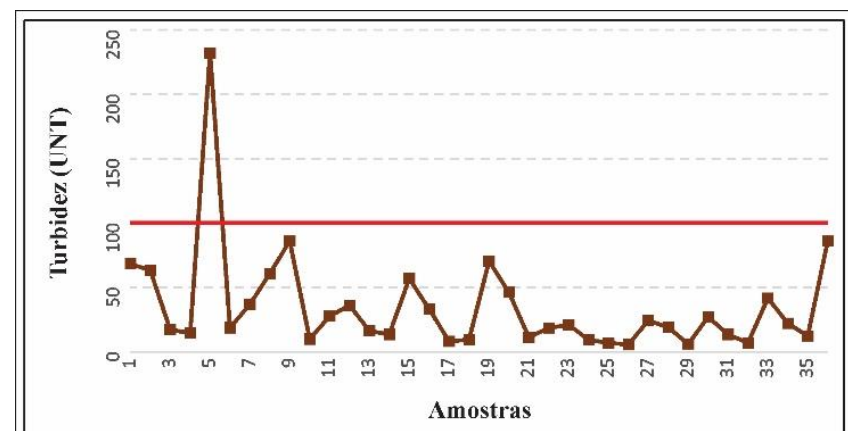

A

$\rightarrow$ Série de dados de Turbidez Limite da DN

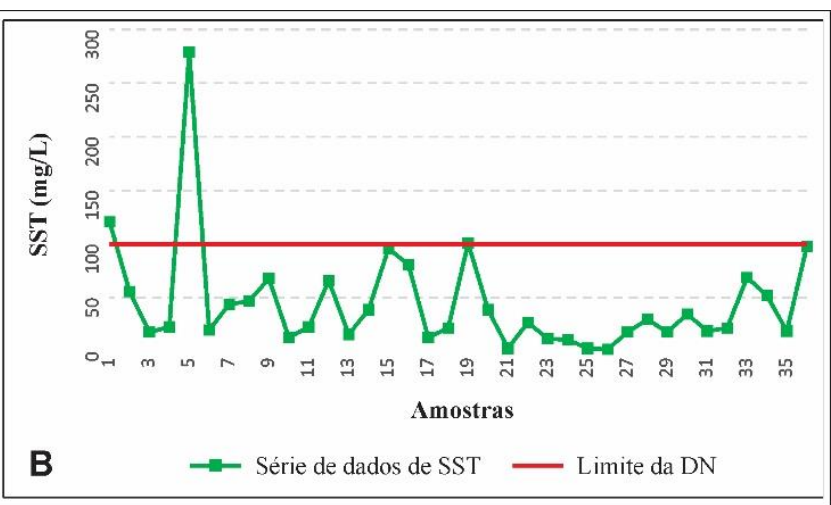

Figura 4 - Verificação gráfica do comportamento dos parâmetros turbidez e SST entre 2007 e 2017

Fonte: Autores, 2019.

Das 36 amostras de turbidez apenas uma posicionou-se acima do limite permitido pela Deliberação Normativa 01/2008 (coleta de 05/11/2008), enquanto o parâmetro de sólidos em suspensão totais obteve três amostras que superaram o limite legal estabelecido (coletas de 06/11/2007, 05/11/2008 e 05/11/2012).

As estatísticas descritivas dos dados apontam para a ocorrência de amostras outliers referentes à coleta do dia 05/11/2008, em ambos os parâmetros (Figura 5). A média obtida para o parâmetro turbidez foi de 34,8 UNT, com amplitude de 226,4 UNT e mediana de 19,9 UNT; enquanto o parâmetro sólidos em suspensão totais obteve média de $45,1 \mathrm{mg} . \mathrm{L}^{-1}$, com amplitude de $277 \mathrm{mg} . \mathrm{L}^{-1}$ e mediana de $25 \mathrm{mg} \cdot \mathrm{L}^{-1}$.

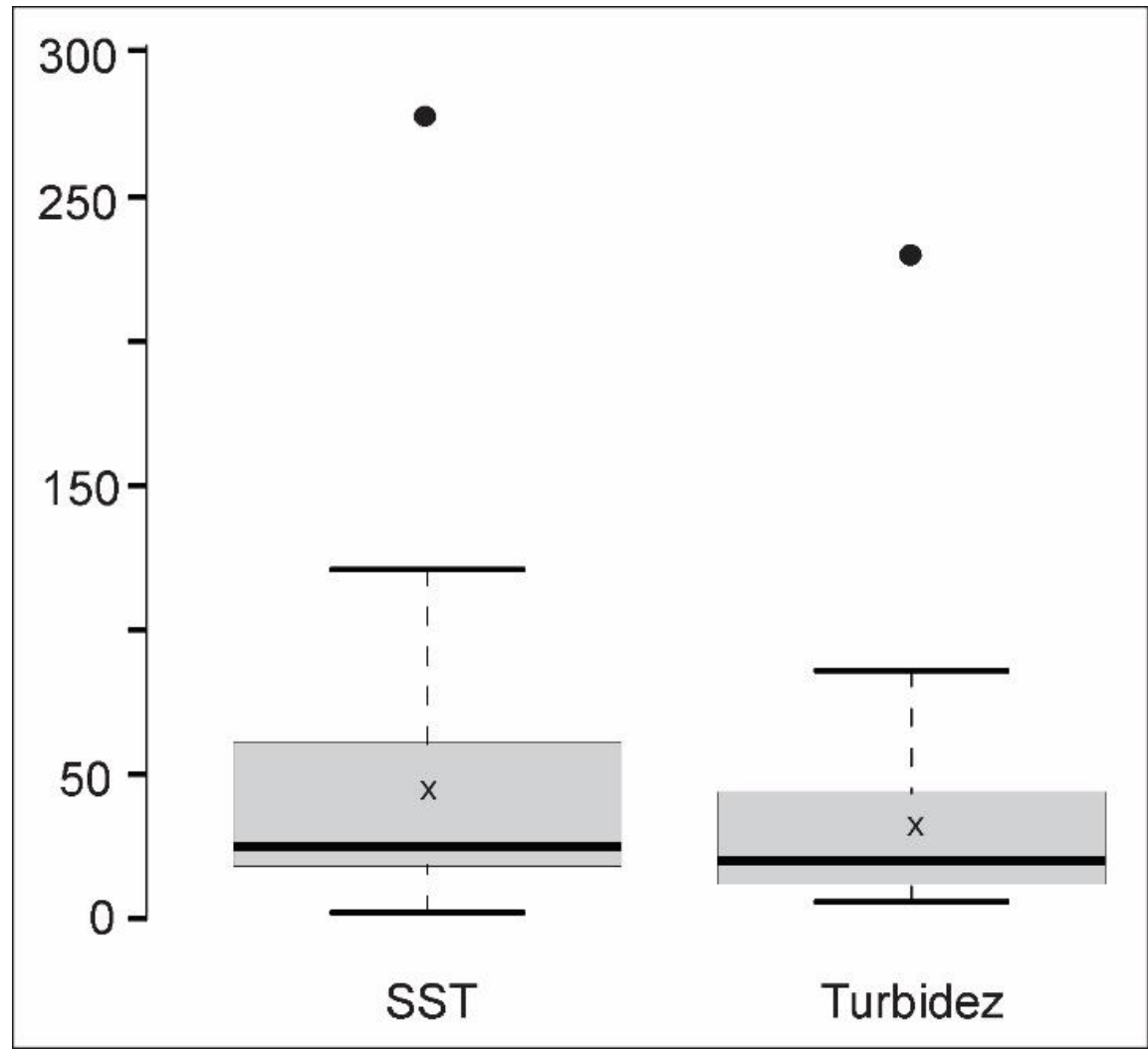

Figura 5 - Boxplot das amostras de turbidez e sólidos em suspensão totais do rio Machado (2007 a 2017)

Fonte: Autores, 2019. 
A dinâmica sedimentar é influenciada expressivamente, nos tipos climáticos intertropicais, pela ocorrência de precipitações líquidas. Cabe ressaltar que a identificação dos perfis de precipitação é uma variável importante na compreensão dos processos erosivos em vertentes (MONTEBELLER, 2009), pois as mesmas caracterizam-se por serem áreas-fonte de sedimentos destinados aos sistemas fluviais e, consequentemente, à dinâmica sedimentar nos canais.

A influência dos perfis de precipitação está relacionada ao momento em que a precipitação atinge a intensidade máxima, além do volume precipitado anteriormente a este instante, pois a umidade antecedente do solo intervém na taxa de infiltração ao longo do tempo e no início do escoamento superficial.

Existem quatro tipos de perfis de precipitação de acordo com Montebeller (2009), (1) o perfil constante, (2) perfil exponencial decrescente, (3) perfil duplo-exponencial adiantado e (4) o perfil duplo-exponencial atrasado. Este último perfil relaciona-se à maior probabilidade de ocorrência de erosão hídrica, devido ao pico da intensidade pluviométrica ocorrer após a precipitação de um certo volume, o que ocasiona o preenchimento dos poros do solo por água e redução gradativa da taxa de infiltração.

Em virtude da baixa densidade de estações que registram dados de intensidade pluviométrica na bacia hidrográfica do rio Machado e arredores, optou-se pela lâmina acumulada de três dias, para associação com a dinâmica sedimentar em suspensão. Este critério foi utilizado por Chleborad (2000) em Seattle nos Estados Unidos na tentativa de prever ocorrência de deslizamentos, bem como Quinta Ferreira (2006) para o correlacionamento com áreas susceptíveis a deslizamentos em Coimbra.

Na Figura 6 apresenta-se a dinâmica sedimentar em suspensão nas datas de amostragem, além da lâmina precipitada de três dias anteriores às coletas. Nota-se que graficamente há o relacionamento entre a lâmina acumulada e o comportamento do parâmetro concentração de sedimento em suspensão (que pode ser compreendido de forma similar ao parâmetro sólidos em suspensão totais).

Tendo por base a análise quantitativa de correlação Pearson (R), obteve-se o ajuste entre a precipitação acumulada de três dias (P-3) e concentração de sedimento em suspensão (CSS) de 0,7601 e entre P-3 e turbidez de 0,7188. Com relação ao coeficiente de determinação $\left(\mathrm{R}^{2}\right)$ alcançou-se o ajuste de 0,6929 entre P-3 e CSS, em função polinomial de segunda ordem. Neste sentido, pode-se estatisticamente estimar a CSS tendo a lâmina acumulada de três dias de antecedência com certo grau de acurácia.

Quanto a eventos ao longo dos dados amostrados no período de 2007 a 2017, destacam-se os eventos pluviométricos que antecederam o dia 05/11/2008, que totalizaram uma lâmina média de $71,2 \mathrm{~mm}$ na bacia de contribuição, refletindo em uma resposta da concentração de sedimento em suspensão (CSS) de 279 mg. $\mathrm{L}^{-1}$. 


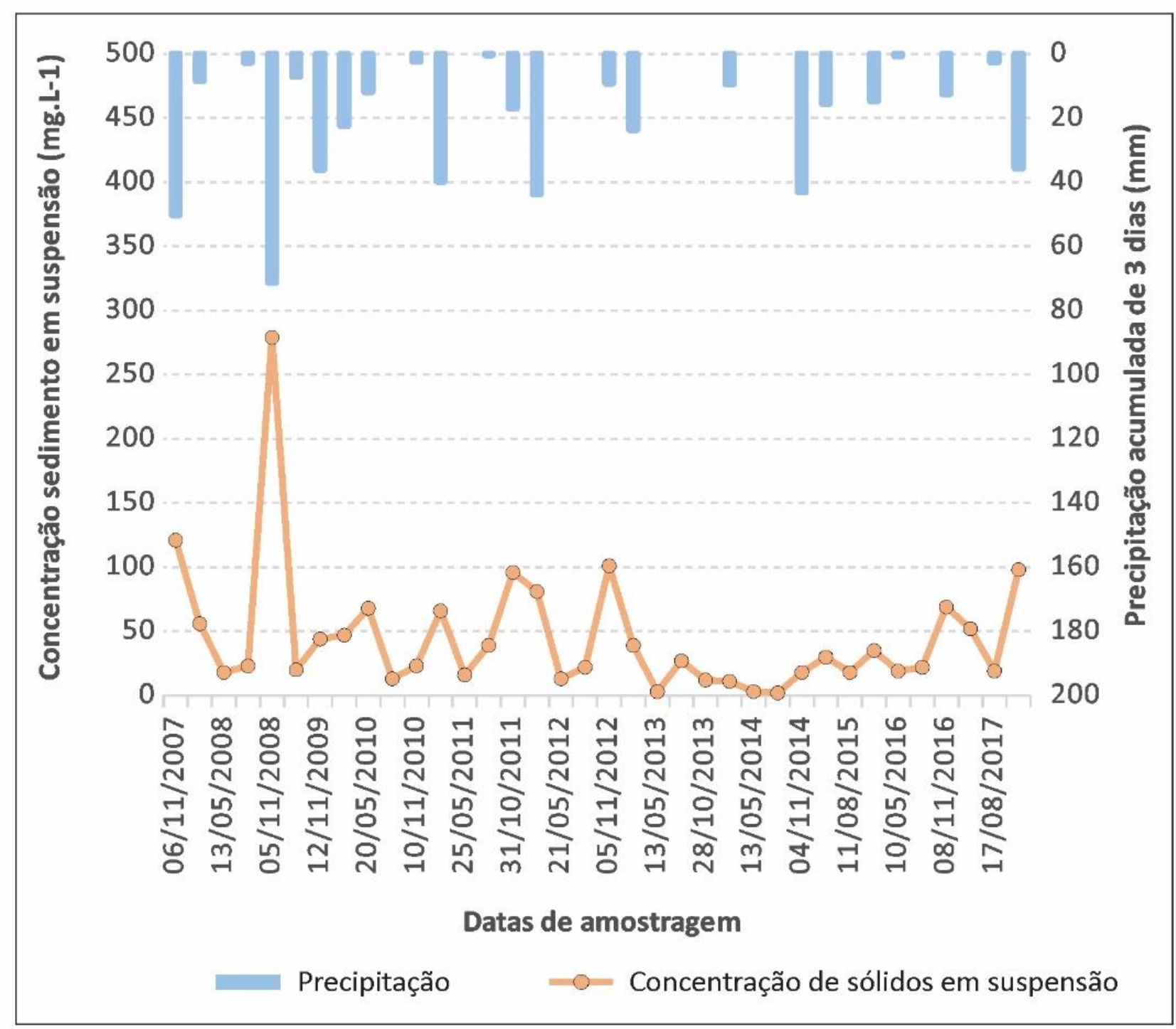

Figura 6 - Dinâmica da concentração de sedimento em suspensão e precipitação acumulada (2007 a 2017) Fonte: Autores, 2019.

A média obtida pela CSS foi de 45,1 mg. $\mathrm{L}^{-1}$ e realizando-se a análise gráfica dos desvios amostrais em relação à média (Figura 7), por meio da tendência observada da média móvel no período de dois anos, infere-se que não há oscilações/rupturas entre períodos distintos para a dinâmica sedimentar em suspensão do rio Machado.

Entretanto, esta afirmação deve ser melhor aferida, devido às características amostrais realizadas pelo IGAM. O ideal é que se tenham dados diários de turbidez e, ao menos, dados semanais de concentração de sedimentos em suspensão, sustentados por ajustes estatísticos satisfatórios na correlação Pearson $(0,9447)$ e no coeficiente de determinação $(0,8923$ - Figura 8$)$, para a estimativa de CSS. 


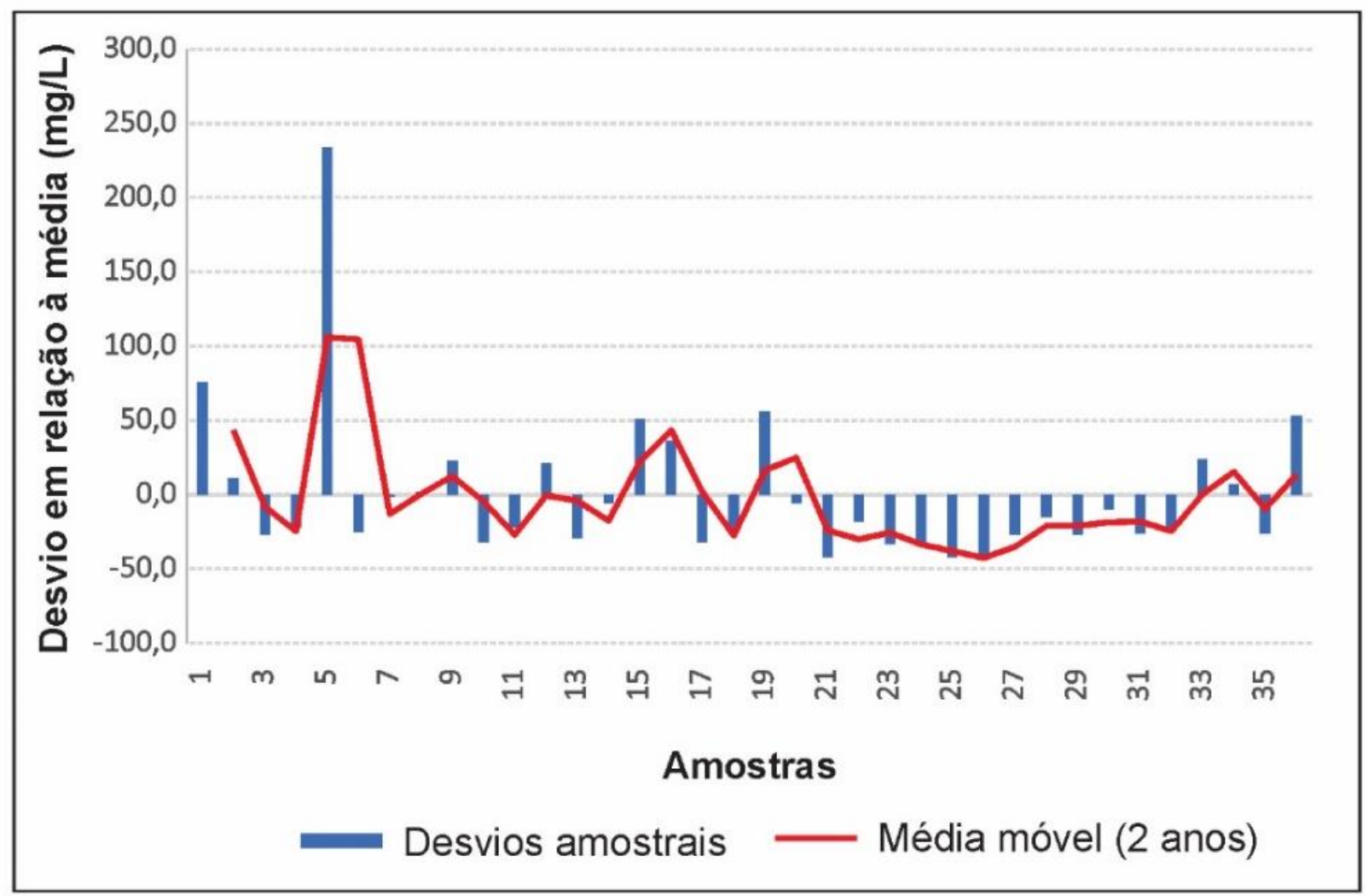

Figura 7 - Desvios amostrais em relação à média (2007 a 2017)

Fonte: Autores, 2019.

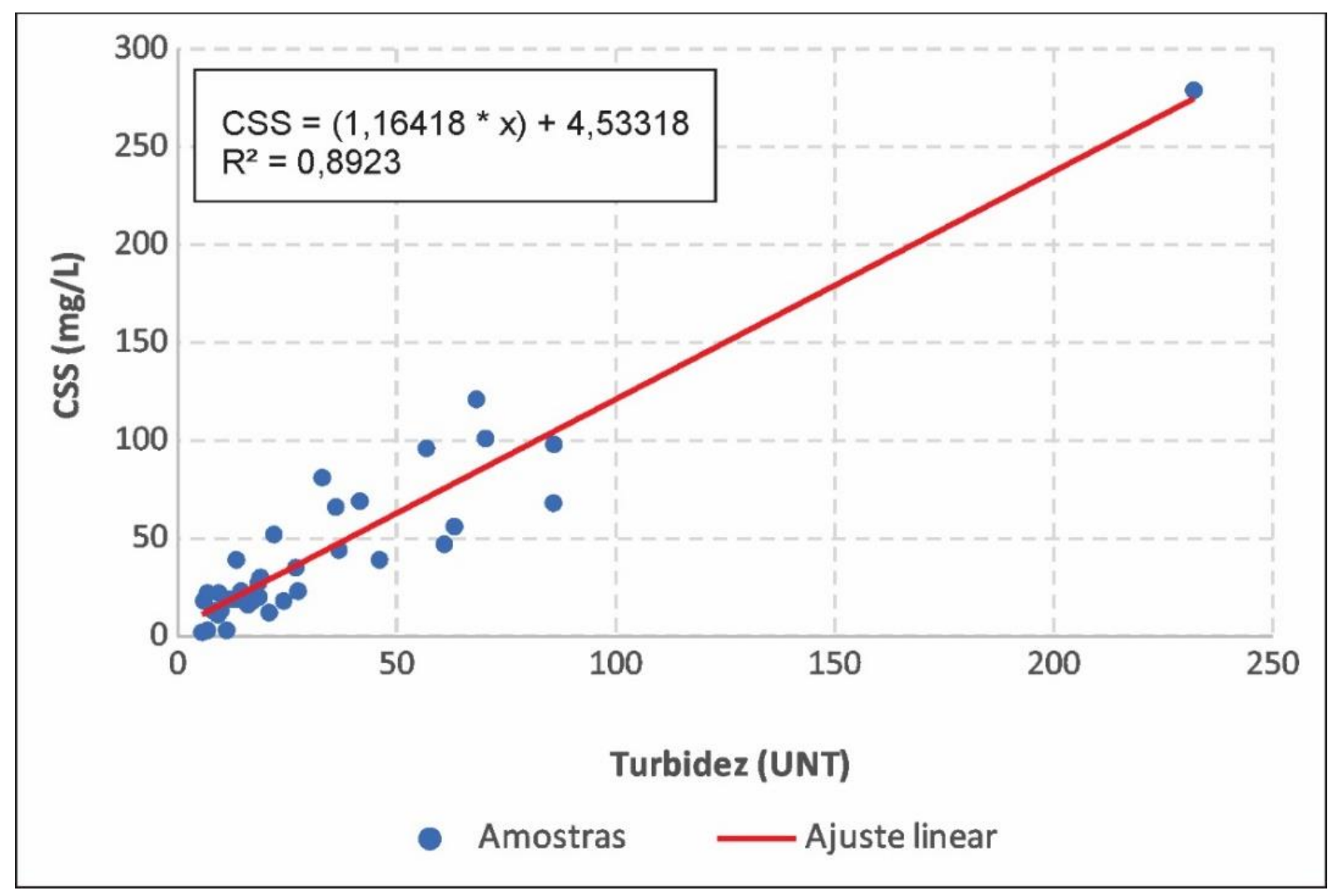

Figura 8 - Ajuste de regressão linear entre turbidez e CSS no período de 2007 a 2017

Fonte: Autores, 2019. 
Os dados diários de turbidez podem ser adquiridos via sonda permanentemente submersa ou pela leitura manual do observador no momento da averiguação da cota do rio Machado. Ainda há a possibilidade da instalação de boia que realiza medições de diversos parâmetros de qualidade de água, sendo seus dados transmitidos via remota (estação telemétrica) ou obtidos em períodos de tempos pré-estabelecidos.

No que tange à descarga sólida em suspensão (t.dia $\left.{ }^{-1}\right)$, baseando-se sua estimativa pela Equação 1, inferiu-se para as 36 amostras o quantitativo de aporte sedimentar tendo como referência as vazões registras na planilha de dados do IGAM, que são semelhantes aos dados registrados na estação fluviométrica da ANA no rio Machado (código: 61568000).

As estatísticas descritivas dos 36 dados de descarga sólida em suspensão (Figura 9A) apontam para a ocorrência de quatro amostras outliers, ou seja, amostras com dados discrepantes referentes às coletas dos dias 06/11/2007 (163,6 t.dia $\left.{ }^{-1}\right)$, 05/11/2008 (459 t.dia $\left.{ }^{-1}\right)$, 14/02/2012 (185,9 t.dia $\left.{ }^{-1}\right)$ e 12/02/2013 (148,5 t.dia $\left.{ }^{-1}\right)$. A média obtida para o parâmetro QSS foi de 49,9 t.dia ${ }^{-1}$, com erro padrão da média em 13,9 t.dia ${ }^{-1}$, amplitude de 458,4 t.dia ${ }^{-1}$, mediana de 16,4 t.dia ${ }^{-1}$ e desvio padrão de 83,9 t.dia ${ }^{-1}$.

Para uma caracterização mais próxima do comportamento mais frequente do rio Machado, optou-se pela remoção dos quatro outliers identificados anteriormente (Figura 9B). Os descritores atualizados apontam uma redução da média para 26,3 t.dia ${ }^{-1}(-47,3 \%)$, com erro padrão da média em 4,5 t.dia ${ }^{-1}(-67,6 \%)$, amplitude de 80,9 t.dia ${ }^{-1}(-82,4 \%)$, mediana de 15,2 t.dia' $(-7,3 \%)$ e desvio padrão de 25,4 t.dia ${ }^{-1}(-69,7 \%)$.

Mesmo com os dados outliers $(\mathrm{n}=36)$ houve um ajuste considerado satisfatório na correlação Pearson $(\mathrm{R}=0,7777)$ e para o coeficiente de determinação da regressão linear $\left(\mathrm{R}^{2}=\right.$ 0,7749), em um ajuste polinomial de $2^{\mathrm{a}}$ ordem, levando-se em consideração os parâmetros P-3 e QSS.

A expressiva maioria das curvas de descargas sólidas em suspensão ajustadas por diversos pesquisadores utilizam os parâmetros vazão (Q) e concentração de sedimentos em suspensão (CSS), entretanto para a bacia hidrográfica do rio Machado o ajuste não atingiu índices considerados satisfatórios $\left(\mathrm{R}^{2} \geq 0,70\right)$ e, neste sentido, optou-se pelo ajuste da curva de descarga, utilizando-se em vez do parâmetro vazão, o parâmetro precipitação acumulada de três dias (Figura 10).

Tal ajuste caracteriza-se por ser algo pouco presente na literatura científica da área de hidrossedimentologia, o que confere ao mesmo, caráter inovador. Optou-se por manter e apresentar tal ajustamento estatístico, pois as obtenções de dados de precipitação são mais confiáveis quando comparados a dados de vazão, que utilizam o método de curva-chave a partir da cota linimétrica (SILVA, 2005), em sua expressiva maioria. 


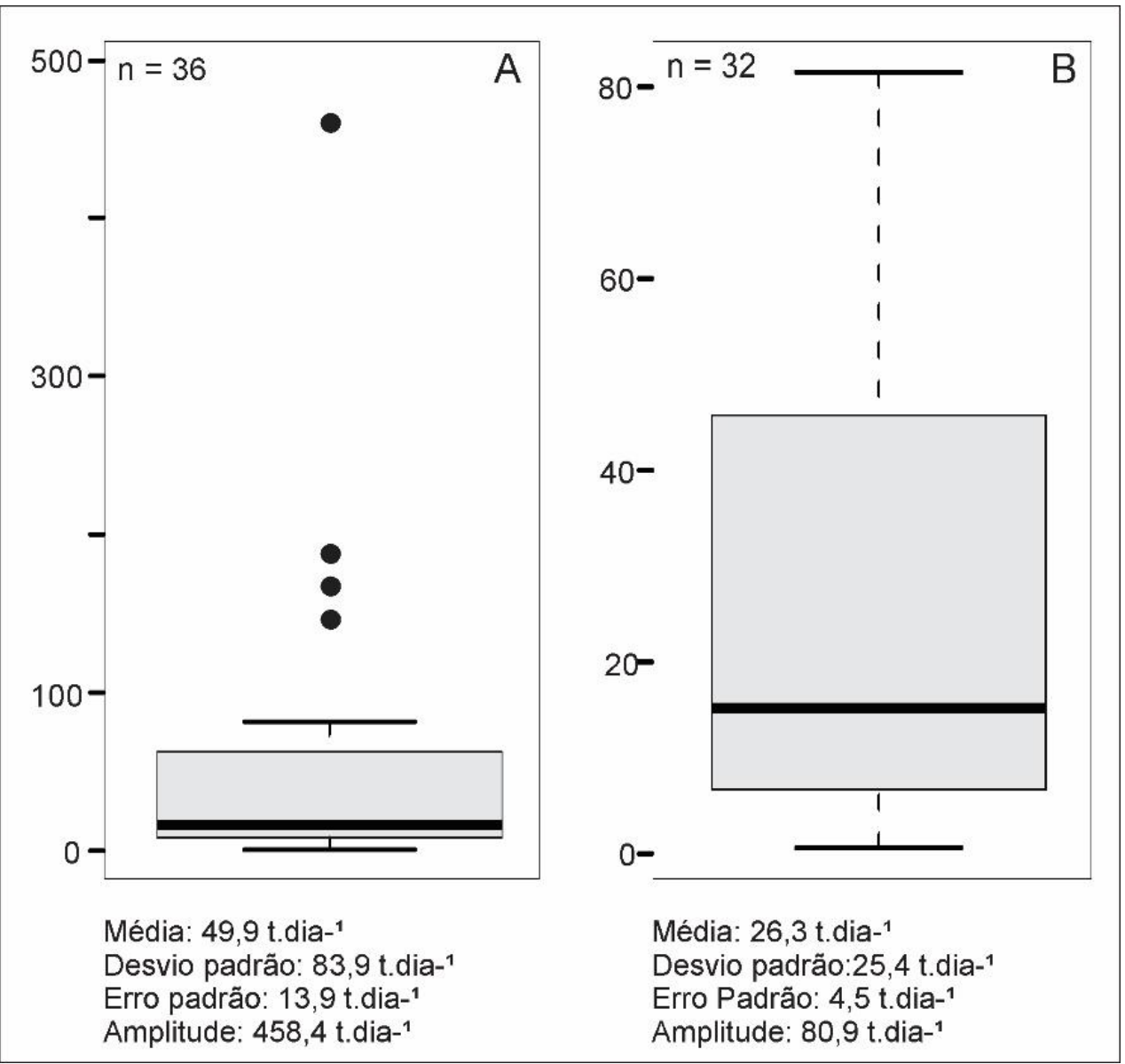

Figura 9 - Boxplots de descarga sólida em suspensão no período de 2007 a 2017 Fonte: Autores, 2019.

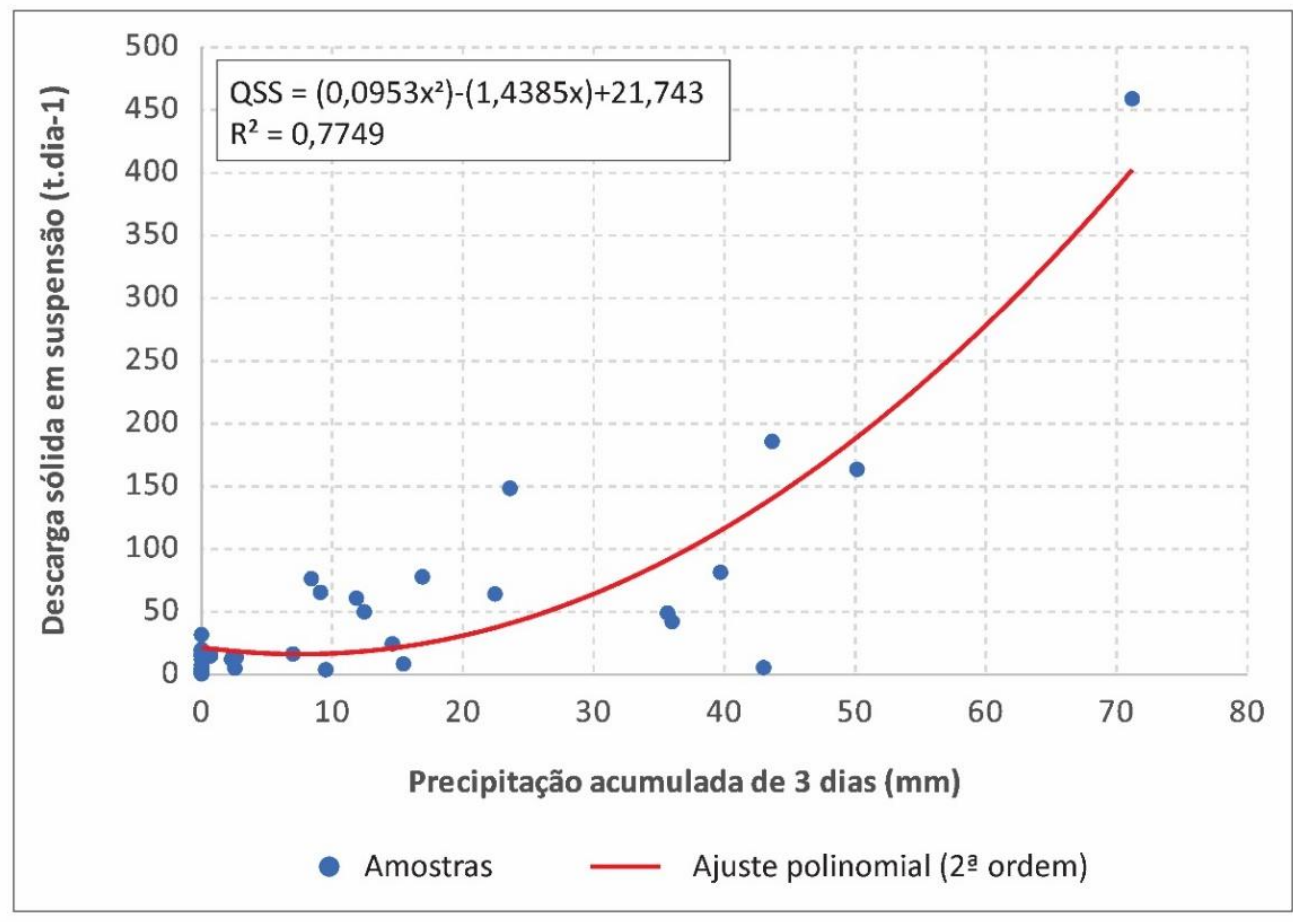

Figura 10 - Curva de descarga sólida da seção Rio Machado no período de 2007 a 2017 Fonte: Autores, 2019. 
A partir da calibração desta curva de descarga, possibilita-se a estimativa da descarga sólida em suspensão a partir do monitoramento pluviométrico médio na bacia hidrográfica do rio Machado. Ressalta-se que, mesmo a rede de observação pluviométrica sendo deficiente na bacia em estudo (apenas 2 postos), a utilização de sensores orbitais como o Hidroestimador ou o CHIRPS poderá fomentar o acompanhamento do aporte sedimentar afluente ao lago de Furnas, devido sua alta resolução espacial.

\section{CONSIDERAÇÕES FINAIS}

O conhecimento da dinâmica hidrossedimentológica em bacias hidrográficas brasileiras ainda permanece um desafio em pleno início do século XXI. Muitos destes desafios passam pela, incapacidade ou ingerência, da destinação de investimentos governamentais para a instalação e manutenção de redes hidrométricas de monitoramento de dados sobre os sistemas fluviais.

As complexidades enfrentadas a partir das características de paisagens no Brasil, bem como as diversas nuances geográficas ao longo do território, aliados à intensa transformação da paisagem pelas ações antrópicas, fazem com que não tenhamos um programa conciso de densificação e atualização da rede já existente, de maneira que atenda a fluidez da produção do espaço.

O monitoramento de dados pluviométricos e fluviométricos tem avançado no Brasil, com utilização de plataformas com conexão via internet ou satélite. Entretanto, dados a respeito de qualidade de água ainda permanecem expressivamente carentes. A Resolução Conjunta ANA/ANEEL n ${ }^{\circ}$ 03/2010 é sem dúvida um avanço, porém balizar a instalação de estações apenas pelo viés da área de drenagem é desconsiderar as características locais e regionais do território brasileiro.

Resultados obtidos por este estudo apontam ajustes estatísticos satisfatórios entre parâmetros de qualidade da água, mais especificamente entre dados de turbidez e sólidos em suspensão totais, além do ajuste da curva de descarga sólida em suspensão, relacionando-os à variável de precipitação acumulada de três dias.

A partir da análise da descritiva dos dados de descarga sólida, obteve-se a média de contribuição na seção monitorada, no entanto deve-se inclinar esforços no que tange à densificação da rede de monitoramento hidrossedimentométrica na bacia hidrográfica do rio Machado, para a melhor compreensão da dinâmica espaço-temporal do aporte ao lago de Furnas. 


\section{AGRADECIMENTOS}

Os autores agradecem especialmente à ARPA Rio Grande e ao Ministério Público do Estado de Minas Gerais pelo fomento do projeto "Diagnóstico geoambiental da APA da bacia hidrográfica do rio Machado/MG”, com recursos advindos de cobranças de multas ambientais emitidas pelo Instituto Estadual de Florestas.

\section{REFERÊNCIAS}

ALVARES, C. A. et al. Köppen's climate classification map for Brazil. Meteorologische Zeitschrift, v. 22, n. 6 (2013), p. 711 - 728, 2013. DOI: https://dx.doi.org/10.1127/0941-2948/2013/0507.

ANA (Agência Nacional de Águas). Apostila do curso de Qualidade da Água em Reservatórios. Disponível em: <http://capacitacao.ana.gov.br/conhecerh/handle/ana/74> . Acesso em: 27 abr. 2019.

BERALDO, A. F.; SALDANHA, R. F. Estatística V: Análise Multivariada: Apostila de curso em Análise Multivariada, 2016. Disponível em: <http://www.ufjf.br/antonio_beraldo/cursos/analisemultivariada/>. Acesso em: 15 dez. 2016.

BERTONI. J.; LOMBARDI NETO, F. Conservação do Solo. São Paulo: Ícone, 1990.

BRASIL. Resolução no 357 de 17 de março de 2005. Disponível em: <http://www2.mma. gov.br/port/conama/legiabre.cfm?codlegi=459> . Acesso em: 05 mar. 2019.

CARVALHO, N. O.; FILIZOLA JÚNIOR, N. P.; SANTOS, P. M. C.; LIMA, J. E. F. W. Guia de avaliação de assoreamento de reservatórios. Brasília: ANEEL, 2000. 140p.

CARVALHO, N. O. Hidrossedimentologia Prática. Rio de Janeiro: CPRM e ELETROBRÁS, 1994. 400p.

CEMIG (Companhia Energética de Minas Gerais). Pequenas Centrais Hidrelétricas. Disponível em: 〈http://www.cemig.com.br/pt-br/a_cemig/Nossa_Historia/Paginas/Pch.aspx >. Acesso em: 01 fev. 2019.

CHLEBORAD, A. Preliminary method for anticipating the occurrence of precipitation-induced landslides in Seattle, Washington. USGS, File report 00-469, 2000.

CHRISTOFOLETTI, A. Geomorfologia Fluvial. São Paulo: Edgard Blücher, 1981.

CPRM (Companhia de Pesquisa de Recursos Minerais). Mapa geológico no Estado de Minas Gerais. 2014. Disponível em: <http://www.portalgeologia.com.br/>. Acesso em: 03 jun. 2018.

CUNHA, S. B. Geomorfologia Fluvial. In: CUNHA, S. B.; GUERRA, A. J. T. (Orgs.) Geomorfologia: Uma Atualização de Bases e Conceitos. 4. ed. Rio de Janeiro: Bertrand Brasil, 2001.

FURNAS (Furnas Centrais Elétricas S.A). Dados da Usina Hidrelétrica de Furnas. Disponível em: <http://www.furnas.com.br/subsecao/120/usina-de-furnas---1216-mw>. Acesso em: 25 abr. 2019.

GREGÓRIO, D. H. S.; FERREIRA, M. F. M. Compartimentos de relevo da Área de Proteção Ambiental da bacia hidrográfica do rio Machado. In: V Jornada Científica da Geografia, 2018. Alfenas. Anais... Alfenas (MG): Universidade Federal de Alfenas. 5p. 
GUERRA, A. J. T. O Início do Processo Erosivo. In: GUERRA, A. J. T.; SILVA, A. S.; BOTELHO, R. G. M. (Orgs.). Erosão e Conservação dos Solos: Conceitos, Temas e Aplicações. Bertrand Brasil: Rio de Janeiro, 1999.

HOROWITZ, A. J. An evaluation of sediment rating curves for estimating suspended sediment concentrations for subsequent flux calculations. Hydrological Process, 17, 2003, 3387-3409.

IBGE (Instituto Brasileiro de Geografia e Estatística). Censo agropecuário brasileiro de 2017. Disponível em: 〈https://censos.ibge.gov.br/agro/2017/〉. Acesso em: 28 ago. 2018.

Estimativa populacional de Machado/MG e Poço Fundo/MG. Disponível em: <https://cidades.ibge.gov.br/brasil/mg/machado/panorama>. Acesso em: 22 mar. 2019.

IGAM (Instituto Mineiro de Gestão de Águas). Dados do monitoramento de qualidade das águas. Disponível em: <http://portalinfohidro.igam.mg.gov.br/>. Acesso em: 10 jan. 2019.

INMET (Instituto Nacional de Meteorologia). Normais Climatológicas do Brasil de 1981 a 2010. Disponível em: <http://www.inmet.gov.br/>. Acesso em: 01 mar. 2019.

LATUF, M. O.; AMARAL, E. Assessment of suspended sediment discharge in the Purus River basin, Brazil. International Journal of River Basin Management. DOI: 10.1080/15715124.2016.1215322, 2016.

MINAS GERAIS. Deliberação Normativa Conjunta COPAM/CERH-MG 01/2008. 2008. Disponível em: 〈http://www.siam.mg.gov.br/sla/download.pdf?idNorma=8151 $>$. Acesso em: 25 jan. 2019.

MONTEBELLER, C. A. Influência dos perfis de precipitação nas perdas de solo e água. 2009. 87f. Tese de Doutorado (Engenharia Agrícola) - Departamento de Engenharia Agrícola, Universidade Federal de Viçosa, Viçosa, 2009.

OLIVEIRA, J. F.; GRIEBELER, N. P.; CORRECHEL, V.; SILVA, V. C. Erodibilidade e tensão crítica de cisalhamento em solos de estradas não pavimentadas. Revista Brasileira de Engenharia Agrícola e Ambiental, v. 13, p. 955-960, 2009.

PESCADOR. Registro de memória oral. Reunião do Comitê da Bacia Hidrográfica do rio São Francisco. Petrolina, 2011.

PISANI, R. J.; BUENO, V. C.; FIUZA, J. R. Relatório final de diagnóstico do uso e cobertura da terra na APA do rio Machado. Alfenas: UNIFAL, 2018.

PRUSKI, F. F. Conservação de solo e água: práticas mecânicas para o controle da erosão hídrica. 2. ed. Viçosa: Universidade Federal de Viçosa, 2009.

QUINTA FERREIRA, M.; LEMOS, L. J. L.; PEREIRA, L. F. M. Influência da água no desencadear de deslizamentos em Coimbra. Actas... $8^{\circ}$ Congresso Nacional da Água, 13 a 17 de março de 2006. Figueira da Foz.

R CORE TEAM. R: A language and environment for statistical computing. R Foundation for Statistical Computing, Vienna, Austria. URL https://www.R-project.org/. 2018.

REBOITA, M. S.; RODRIGUES, M.; SILVA, L. F.; ALVES, M. A. Aspectos climáticos do estado de Minas Gerais. Revista Brasileira de Climatologia, ano 11, v. 17, p. 206-226, jul/dez, 2015. 
ROSS, J. O. Registro Cartográfico dos Fatos Geomorfológicos e a Questão da Taxonomia do Relevo. 1992. Revista do Departamento de Geografia, v. 6, p. 17-29, 8 nov. 2011.

SHEEDER, S. A.; ROSS, J. D.; CARLSON, T. N. Dual urban and ruralhydrographs signals in three small watersheds. Journal of the American Water Resources Association, Middleburg, v. 38, n. 4, p. 1027-1040, 2002.

SILVA, D. D. Notas de aula - disciplina de Hidrologia. Departamento de Engenharia Agrícola. Universidade Federal de Viçosa, 2005.

TUCCI, C. E. M. (Org.). Hidrologia: Ciência e Aplicação. 4. ed. Porto Alegre: UFRGS/ABRH, 2009.

TUNDISI, J. G.; TUNDISI, T. M. Limnologia. São Paulo: Oficina de Textos, 2008.

UNIVERSIDADE FEDERAL DE VIÇOSA (UFV - CETEC - UFLA - FEAM). Mapa de solos do Estado de Minas Gerais. Belo Horizonte, Fundação Estadual do Meio Ambiente, 2010. 49p. Disponível em: <http://www.dps.ufv.br/?page id=742>. Acesso em: 02 set. 2018.

VON SPERLING, M. Introdução à Qualidade das Águas e ao Tratamento de Esgotos. Belo Horizonte: DESA-UFMG, 452p. 2005.

WALLING, D. E. Assessing the accuracy of suspended sediment rating curves for a small basin. Water Resources Research, 13 (3), 1977, 1-8.

Trabalho enviado em 25/05/2019

Trabalho aceito em 25/06/2019 